Original Article

\title{
Upper extremity muscle activation during drinking from a glass in subjects with chronic stroke
}

\author{
Jung Ah Lee, PhD ${ }^{1)}$, Pil Woo Hwang, BM ${ }^{1)}$, Eun Joo Kim, MD²** \\ 1) Department of Motor and Cognitive Rehabilitation, Korea National Rehabilitation Research \\ Institute, Republic of Korea \\ 2) Department of Rehabilitation Medicine, Korea National Rehabilitation Hospital: Seoul 142-884, \\ Republic of Korea
}

\begin{abstract}
Purpose] The purpose of this study was to compare the muscle activities of upper extremities during a drinking task between the stroke-affected and less-affected sides. [Subjects] Eight stroke patients (8 men; age 45.3 years; stroke duration 21.9 months) participated in this study. [Methods] Electromyography (EMG) was used to measure nine muscle activities of the upper extremity. The drinking task was divided into 5 phases. [Results] Analysis of the EMG data showed that the percentage of maximum voluntary isometric contraction (\%MVIC) across all phases of drinking differed between the affected and less-affected sides. Participants used relatively higher levels of \%MVIC in the anterior deltoid, flexor muscles, brachioradialis, and infraspinatus on the stokeaffected side. [Conclusion] The difference in muscle activation across all phases of the drinking movement allowed us to determine how upper extremity muscle activation may influence drinking performance on the stroke-affected and less-affected sides.

Key words: Drinking, EMG, Stroke
\end{abstract}

(This article was submitted Aug. 21, 2014, and was accepted Oct. 21, 2014)

\section{INTRODUCTION}

Stroke patients exhibit impairment of the upper extremities ${ }^{1)}$, that is, paresis, loss of fractionated movement, abnormal muscle tone and loss of somatosensation ${ }^{2)}$. These impairments affect upper extremity motor functions such as reaching and grasping ${ }^{3-5}$. Impaired shoulder and arm function causes limitations in activities of daily living for the majority of stroke patients.

Drinking is a fundamental component of daily movement and requires coordination in multiple tasks for reaching and grasping. Stroke patients have difficulty with movement strategies for the upper extremities during drinking movements especially in the reaching and drinking phases ${ }^{6-8)}$. Motor aspects of drinking include appropriate activation of the muscles of the shoulder, elbow, and wrist joint for movement of the arm. Activities such as reaching, forward transfer, drinking, back transfer, and return to the resting position can influence task-specific coordination and the coordinated activation of various muscles. Muscle activation patterns provide important information about movement strategies. Vandenberghe et al. investigated the effects of reaching height and width on muscle activities in the upper extrem-

*Corresponding author. Eun Joo Kim (E-mail: silverzookim@gmail.com)

C2015 The Society of Physical Therapy Science. Published by IPEC Inc. This is an open-access article distributed under the terms of the Creative Commons Attribution Non-Commercial No Derivatives (by-ncnd) License $<$ http://creativecommons.org/licenses/by-nc-nd/3.0/> . ity ${ }^{9}$. Their findings show that muscle activity is affected by the width and height of the target. The individual contribution of particular muscles changes when performing different target strategies. Massie et al. investigated the muscle activation pattern of continuous reaching in stroke patients. Their findings show that stroke patients had difficulty with continuous reaching and had distinct strategy differences between the stroke-affected and less-affected sides.

Previous studies have examined the kinematics of drinking of stroke patients. However, the muscle activation pattern of drinking of the intrinsicly impaired movements of hemiplegic upper extremities has not been well documented. Therefore, this study investigated muscle activities in the upper extremity of stroke patients in all phases of the drinking movement.

\section{SUBJECTS AND METHODS}

\section{Subjects}

A convenience sample of 8 patients [ 8 males, age (mean $\pm \mathrm{SD}) 45.25 \pm 14.44]$ with hemiparesis after stroke was recruited from the National Rehabilitation Hospital and the local community. The inclusion criteria for stroke subjects were: hemiparesis resulting from stroke occurring more than six months earlier, and the ability to understand and follow verbal instructions. Exclusion criteria were: contracture of the upper extremities, or inability to hold a cup. The chief examiner explained the experimental procedures to the subjects and then asked them to sign an informed consent form before testing began. The subjects' characteristics are presented in Table 1 . 


\section{Methods}

All participants performed a drinking task while seated at an adjustable-height table in a straight-backed, adjustablechair, which was adjusted so that their hip and knee joints were in $90^{\circ}$ flexion. The drinking cup was $7 \mathrm{~cm}$ in diameter and $9.5 \mathrm{~cm}$ high. A 6-cm diameter ball was inserted in the cup instead of water. Surface EMG activity was recorded from the supraspinatus, anterior deltoid, posterior deltoid, biceps brachii, triceps brachii, brachioradialis, infraspinatus, flexor carpi radialis, and extensor carpi radialis muscles of the affected and less-affected sides. Each participant's skin was carefully prepared to reduce skin impedance to a level below $5 \mathrm{k} \Omega$ by dry-shaving hair with a disposable razor and cleansing the skin with a $2 \%$ alcohol swab. EMG wireless electrodes, $\left(37 \times 26 \times 15 \mathrm{~mm}\right.$ in size; Trigno $^{\mathrm{TM}}$ EMG Systems, Delsys Inc., Boston, MA, USA) were placed over the belly of each muscle ${ }^{10)}$. The raw EMG signal for each muscle was recorded at a sampling rate of $2,000 \mathrm{~Hz}$ and processed using a $60-\mathrm{Hz}$ notch filter. The EMG signal was full-wave rectified and filtered using a band-pass filter between $20-450 \mathrm{~Hz}^{11)}$. The maximal voluntary isometric contraction (MVIC) of each muscle was recorded for $5 \mathrm{~s}$ and averaged over the middle $3 \mathrm{~s}$ of the EMG signal to provide a stable reference value for EMG normalization of the target muscles. Drinking task measurements were recorded for the 5 phases of the action: reaching for the cup, forward transport of the cup to the mouth, drinking, back transport of the cup to the table, and returning the hand to the resting initial position ${ }^{12}$. Wilcoxon's signed rank test was used to compare the differences in activities of the nine upper extremity muscles (\%MVIC) across all 5 phases of the action of drinking from a cup between the affected and less-affected sides. SPSS for Windows, version 21.0 (SPSS Inc., Chicago, IL, USA) was used for statistical analysis and statistical significance was accepted for values of $\mathrm{p}<0.05$.

\section{RESULTS}

All participants activated all 9 muscles (anterior deltoid, posterior deltoid, biceps brachii, triceps brachii, forearm flexor, forearm extensor, brachioradialis, supraspinatus, and infraspinatus) during the drinking task (reaching, forward transfer, drinking, backward transfer, and initial returning phases).

There were significant differences in \%MVIC among the muscles between the stroke-affected and less-affected sides $(p<0.05)$. There were significant difference in \%MVIC data of the forearm flexor, brachioradialis, and infraspinatus during the reaching phase; in \%MVIC data of the anterior deltoid, brachioradialis, the infraspinatus during the forward transfer phase and the drinking phase; in \%MVIC data of the anterior deltoid, and infraspinatus during the back transfer phase; and in \%MVIC data of the anterior deltoid during the return phase (Table 2).

\section{DISCUSSION}

We observed a significant difference in the muscle activation of the upper extremities during the drinking task
Table 1. General characteristics of the subjects

\begin{tabular}{lc}
\hline Variables & Stroke \\
\hline Age (years) & $45.3(14.4)$ \\
Gender (male) & 8 \\
Height (cm) & $171.8(5.0)$ \\
Weight (kg) & $71.6(9.7)$ \\
Onset duration (months) & $21.9(42.2)$ \\
Lesion Side (Rt/Lt) & $(4 / 4)$ \\
Etiology (infarction/hemorrage) & $(6 / 2)$ \\
Upper FMA (0-66 scores) & $55.6(8.2)$ \\
MMSE-K (scores) & $28.9(1.9)$ \\
\hline Mean (SD), Rt: Right, Lt: Left, FMA: Fugl- \\
Meyer Assessment, MMSE-K: mini mental state \\
examination-Korean version
\end{tabular}

between the stroke-affected and less-affected sides. There was greater effort on the affected side in the anterior deltoid during the forward transfer, drinking, backward transfer, and return phases than on the less-affected side. The muscle activity pattern of the anterior deltoid depicts its main role in the forward transfer, drinking, backward transfer, and return phases of the drinking task. The brachioradialis and infraspinatus muscles were more prominently involved in reaching, forward transfer of the cup to the mouth, and drinking performance than the other muscles. Other studies have investigated the degree in muscle activation in the upper limb muscles during reaching movements in patients recovering from stroke. Their findings show that the muscle activities of the deltoid anterior fibers and the triceps of the non-paretic side are larger than those of the paretic side during low reaching movements ${ }^{13)}$. Wagner et al. investigated the activation and recovery of the upper extremity muscles during the first few months after stroke ${ }^{4}$. Their findings show that muscle activities differ in relation to changes in tasks performed using the upper extremity. Our results demonstrate that the stroke-affected side has relatively higher levels of muscle activation than the less-affected side. This is because of increased effort of recruitment due to the decreased numbers of functional motor units on the paretic $\operatorname{side}^{4,14)}$.

Information about the differences in muscle activation across all phases of the drinking movement enables determination of how upper extremity muscle activation may influence drinking performance on the stroke-affected and less-affected sides. The results of the present study could be utilized in task-oriented motor control and robot-mediated therapy for individuals with impaired upper extremity function after stroke.

\section{ACKNOWLEDGEMENT}

This research was supported by the Ministry of Trade, Industry and Energy (grant no. 70011192). 
Table 2. EMG activities of 9 muscles during the 5 phases of the drinking task

\begin{tabular}{llccccc}
\hline stroke & $\begin{array}{c}\text { Reaching phase } \\
(\% \mathrm{MVIC})\end{array}$ & $\begin{array}{c}\text { Forward transfer } \\
\text { phase }(\% \mathrm{MVIC})\end{array}$ & $\begin{array}{c}\text { Drinking phase } \\
(\% \mathrm{MVIC})\end{array}$ & $\begin{array}{c}\text { Backward transfer } \\
\text { phase }(\% \mathrm{MVIC})\end{array}$ & $\begin{array}{c}\text { Returning phase } \\
(\% \mathrm{MVIC})\end{array}$ \\
\hline $\mathrm{Ad}$ & Affected & $31.1 \pm 15.4$ & $28.1 \pm 11.8^{*}$ & $33.9 \pm 13.6^{*}$ & $28.5 \pm 12.4^{*}$ & $17.4 \pm 7.9^{*}$ \\
& Less-affected & $19.9 \pm 5.3$ & $17.1 \pm 6.7$ & $20.0 \pm 5.4$ & $16.3 \pm 4.1$ & $7.8 \pm 3.3$ \\
$\mathrm{Pd}$ & Affected & $8.4 \pm 4.7$ & $8.5 \pm 4.7$ & $8.9 \pm 4.7$ & $9.3 \pm 5.1$ & $10.4 \pm 5.3$ \\
& Less-affected & $6.0 \pm 3.3$ & $5.2 \pm 2.9$ & $5.5 \pm 3.2$ & $6.2 \pm 3.8$ & $8.5 \pm 5.5$ \\
$\mathrm{Bb}$ & Affected & $14.8 \pm 9.9$ & $28.8 \pm 16.2$ & $23.7 \pm 17.8$ & $18.8 \pm 10.9$ & $17.5 \pm 8.0$ \\
& Less-affected & $8.0 \pm 8.2$ & $13.7 \pm 9.9$ & $9.1 \pm 7.1$ & $10.1 \pm 9.0$ & $8.1 \pm 6.9$ \\
$\mathrm{~Tb}$ & Affected & $12.0 \pm 5.0$ & $9.5 \pm 3.8$ & $9.3 \pm 4.8$ & $12.1 \pm 4.8$ & $9.8 \pm 3.6$ \\
& Less-affected & $9.7 \pm 7.4$ & $8.4 \pm 8.9$ & $7.5 \pm 5.9$ & $8.1 \pm 5.8$ & $8.9 \pm 7.8$ \\
$\mathrm{Fm}$ & Affected & $8.2 \pm 2.3^{*}$ & $10.4 \pm 2.7$ & $7.2 \pm 2.7$ & $7.5 \pm 2.4$ & $10.7 \pm 3.1$ \\
& Less-affected & $4.3 \pm 1.7$ & $7.7 \pm 4.8$ & $6.1 \pm 3.1$ & $6.4 \pm 4.1$ & $8.0 \pm 2.5$ \\
$\mathrm{Em}$ & Affected & $30.6 \pm 20.7$ & $28.7 \pm 16.9$ & $27.1 \pm 16.0$ & $28.7 \pm 13.4$ & $30.7 \pm 14.8$ \\
& Less-affected & $27.7 \pm 14.8$ & $27.0 \pm 18.6$ & $26.1 \pm 17.6$ & $28.7 \pm 15.1$ & $26.4 \pm 14.1$ \\
$\mathrm{~B}$ & Affected & $15.0 \pm 6.1^{*}$ & $22.5 \pm 6.7^{*}$ & $16.7 \pm 5.7^{*}$ & $16.9 \pm 7.0$ & $17.9 \pm 5.4$ \\
& Less-affected & $8.5 \pm 4.9$ & $13.1 \pm 6.0$ & $10.6 \pm 4.4$ & $10.6 \pm 5.4$ & $11.3 \pm 4.8$ \\
$\mathrm{~S}$ & Affected & $20.7 \pm 9.9$ & $30.2 \pm 10.9$ & $36.2 \pm 18.6$ & $22.7 \pm 8,8$ & $25.0 \pm 8.3$ \\
& Less-affected & $21.0 \pm 12.4$ & $32.4 \pm 7.8$ & $32.1 \pm 9.1$ & $23.74 \pm 7.21$ & $40.1 \pm 15.0$ \\
$\mathrm{I}$ & Affected & $28.4 \pm 10.1^{*}$ & $29.2 \pm 11.9^{*}$ & $37.9 \pm 21.1^{*}$ & $28.0 \pm 13.1^{*}$ & $19.4 \pm 8.8$ \\
& Less-affected & $18.9 \pm 8.1$ & $18.0 \pm 5.9$ & $23.1 \pm 7.4$ & $17.9 \pm 4.6$ & $13.0 \pm 5.8$ \\
\hline
\end{tabular}

Values are expressed as Mean SD, ${ }^{*} \mathrm{p} \leq 0.05$, Ad: Anterior deltoid, Pd: Posterior deltoid, Bb: Biceps brachii, Tb: Triceps brachii, Fm: Forearm flexor muscle, Em: Forearm extensor muscle, \% MVIC: Percent maximum voluntary isometric contraction

\section{REFERENCES}

1) Parker VM, Wade DT, Langton Hewer R: Loss of arm function after stroke: measurement, frequency, and recovery. Int Rehabil Med, 1986, 8 69-73. [Medline]

2) Lang CE, Bland MD, Bailey RR, et al.: Assessment of upper extremity impairment, function, and activity after stroke: foundations for clinica decision making. J Hand Ther, 2013, 26: 104-114, quiz 115. [Medline] [CrossRef]

3) Nowak DA: The impact of stroke on the performance of grasping: usefulness of kinetic and kinematic motion analysis. Neurosci Biobehav Rev, 2008, 32: 1439-1450. [Medline] [CrossRef]

4) Wagner JM, Dromerick AW, Sahrmann SA, et al.: Upper extremity muscle activation during recovery of reaching in subjects with post-stroke hemiparesis. Clin Neurophysiol, 2007, 118: 164-176. [Medline] [CrossRef]

5) Massie CL, Malcolm MP, Greene DP, et al.: Kinematic motion analysis and muscle activation patterns of continuous reaching in survivors of stroke. $\mathrm{J}$ Mot Behav, 2012, 44: 213-222. [Medline] [CrossRef]

6) Alt Murphy M, Willén C, Sunnerhagen KS: Kinematic variables quantifying upper-extremity performance after stroke during reaching and drinking from a glass. Neurorehabil Neural Repair, 2011, 25: 71-80. [Medline] [CrossRef]

7) Molina Rueda F, Rivas Montero FM, Pérez de Heredia Torres M, et al.:
[Movement analysis of upper extremity hemiparesis in patients with cerebrovascular disease: a pilot study]. Neurologia, 2012, 27: 343-347. [Medline] [CrossRef]

8) Lee D, Roh H, Park J, et al.: Drinking behavior training for stroke patients using action observation and practice of upper limb function. J Phys Ther Sci, 2013, 25: 611-614. [Medline] [CrossRef]

9) Vandenberghe A, Levin O, De Schutter J, et al.: Three-dimensional reaching tasks: effect of reaching height and width on upper limb kinematics and muscle activity. Gait Posture, 2010, 32: 500-507. [Medline] [CrossRef]

10) Cram JR, Kasman GS, Holtz J: Introduction to Surface Electromography. Aspen Publishers, 1998

11) Kung PC, Lin CC, Ju MS: Neuro-rehabilitation robot-assisted assessments of synergy patterns of forearm, elbow and shoulder joints in chronic stroke patients. Clin Biomech (Bristol, Avon), 2010, 25: 647-654. [Medline] [CrossRef]

12) Alt Murphy M, Sunnerhagen KS, Johnels B, et al.: Three-dimensional kinematic motion analysis of a daily activity drinking from a glass: a pilot study. J Neuroeng Rehabil, 2006, 3: 18. [Medline] [CrossRef]

13) Park M, Lee M, Song M, et al.: The comparison of muslce activation on low-reaching and high-reaching in patient with stroke. J Phys Ther Sci, 2010, 22: 291-294. [CrossRef]

14) Bourbonnais $D$, Vanden Noven $S$ : Weakness in patients with hemiparesis. Am J Occup Ther, 1989, 43: 313-319. [Medline] [CrossRef] 